\title{
A Review of 'Green Growth: Ideology, Political Economy and the Alternatives'
}

Published: 2 April 2019

Keywords: green growth; green economy; low carbon; just transitions; sustainable development goals

Green Growth: Ideology, Political Economy and the Alternatives

Dale G, Mathai M, Puppim de Oliveira JA (editors)

Zed Books, London, UK. 2016

300 pp.; ISBN: 978-1783604876

This is a challenging book. It tests the reader on a number of fronts including a series of intensive theoretical discourses on the political economy of the green economy, a critique of the neoliberal green growth agenda, and the uncomfortable proposition that the trajectory offered by the green economy has significant implications for the equitable development of society. The ultimatum of the book suggests that the proposed solutions are politically difficult and involve radical social change.

Having recently exprienced a UN Ministerial Summit on the Inclusive Green Economy, the dominant discussions focus upon the neoliberal response to the collective global environmental crisis of climate change, biodiversity loss, waste and pollution intertwined with the deep social crisis of poverty within the global south. The solutions are numerous-mega infrastructure projects focusing on the large-scale deployment of renewable energy, the growth of 'green' SMEs built around social and technical innovation, promoting the circular economy that treats waste as resource, and the emergence of natural capital accounting systems that document and 'value' the natural assets of a nation. These mechanisms and processes are the heart and soul of the new green economy and are designed to promote a 'low carbon' future within the context of a 'just transition'. Personally, I too am a convert of this doctrine, a willing participant in the frame that modern neoliberal democratic capitalism is a force for good that can be harnessed to promote ecological modernisation, the integration of ecological, technical and economic forces for sustainability.

Enter the challenge of this book-a literary 'spanner in the works' that challenges the fundamental nature of the green economy and its socio-political positioning as the dominant mechanism to deliver a low carbon and green future. As a reviewer, my thoughts emerging from this work are of pessimism, doubt and complexity-not in terms of the content, which at times is difficult reading, but in terms of the realisation that the premise of the authors may be correct. The current incremental approach based on ecological modernisation may not be enough to radically structure the global economy in the near term to meet both our climate change and social commitments under Paris and the 2030 Sustainable Development Goals. In fact, as suggested within several chapters, some of the tenants of the green growth paradigm may serve to widen existing inequalities. This is a substantial wake-up call in the context of the growing global response in the form of the green economy, where the linkages are being made between the global chains of globalised large scale financial capital and the sustainability agenda at the expense of localised, decentralised participatory responses. As championed within the text, a paradigm shift is required that addresses the underlying drivers of consumerism and profit within the current economic model, and moves to promote equity, dematerialisation and sufficiency within society.

The scale of the problem is explored in depth in Part 1. Chapter 1 is one of the most compelling reads in the book, detailing the severe nature of the climate crisis and how today's political and economic approach is really based on 'tinkering and tweaking' that will not achieve the wholesale social and economic change required to meet the latest round of climate targets. It articulates that meeting these difficult targets will be impossible under the current (green) 
growth paradigm that embeds consumption and stimulates infinite growth on a finite planet. Chapter 2 explores the interpretation of green growth and seeks to critically examine the relationship between 'green' and 'growth'. A critical perspective on the privatisation and capitalisation of nature is a prevalent theme in this chapter (as it is through the book) exploring and critiquing the notion of ecosystem services and natural capital-a foundation on which much of the lore of green growth depends. The arguments proceed that green growth represents a liberalisation of nature, a conquest followed by monetisation, commercialisation and trade. The author contends that a counterrevolution is needed to contest the green growth narrative recognising that labour struggles are inherently entwined with environmental justice movements. I'm sympathetic to this view as a natural response to the many years of 'environmental' economic monetisation of ecosystem services but what the book is responding to is the tail end extreme of the movement. It fails to capture the essence of what ecosystem services is about, the articulation of our deep connection to nature and the variety of benefits we receive from it. The chapter however services as a warning-if left unchecked, natural capital could promote the commodification and trade of ecosystems. A warning best heeded.

Part 2 explores a number of interesting case studies including Korea, Brazil, EU, Latin America and India. The chapters are well organised and compelling bringing to bear the underlying arguments that the green growth paradigm is essentially a new and aggressive form of capitalism masquerading under environmentalism. I particularly enjoyed the chapter on the EU, which articulated the position of the EU as a founder and supporter of the green growth concept which is woven into a range of positions including its renewable energy and climate targets and the wholesale adoption of market led (and market endorsed) policy instruments. The chapter delves into the contested nature of sustainability in the EU, from the early adoption of the precautionary principle to increasing influence and encroachment of business in reducing and limiting EU environmental ambitions. Ultimately in the EU, as the chapter points out, green growth will flourish and open new markets, new opportunities and new profit-making business but will ultimately fail to solve the underlying structural problems which are eroding Earth's life support systems.

Part 3 leads the reader through a number of responses to the green growth paradigm and a set of alternatives for consideration. In my opinion this the most least developed part of the book and reflects the nature of the debate that while capitalism causes as many problems as it solves [in green growth] there is a lack of a cohesive, comprehensive and pragmatic alternatives that can operate at scale. Chapter 11 on Sustainable Energy Utilites (SEU) is a case in point. An insightful chapter and a promising approach, it argues that the fetishism around eco-technologies, the poster child of the eco-modernisation agenda, has not resolved many issues facing the world's poor. The green economy approach could potentially widen the gulf between the elite and the impoverished by avoiding the grittier issues of social and environmental justice that are necessary for societal change. Many energy reforms in the renewable market 'lock in' massive infrastructure projects and centralised structures based on generous subsidies and supporting policy structures. The outcomes, as noted in the chapter, are to reinforce centralised corporate control of energy infrastructure, locking in inequalities existing in the social and political system. The advent of the SEU as an alternative offers an innovative approach for genuine change, emphasising sufficiency, decentralisation and energy reduction as its business model, but for the near future, it operates, as many projects do, as a niche within the capitalist system, relying on its structures and social norms to survive and thrive. What is needed in Part 3 is further ideas to reinforce and drive the large-scale change necessary for genuine sustainable societies and mass movements, the spread of these niche innovations in to the mainstream and the policies that will be required to support it.

While I am not convinced the book offers much in the way of pragmatic solutions, as a text it is very effective at identifying the problems within the green growth narrative. It holds up a mirror and counter-narrative to the ascendant and dominant paradigm on green growth that is thriving within the UN, the OECD, the G8 and the World Bank and is being propagated within national political structures. As a text and a set of ideas, this is useful as a way to ultimately change the course of green growth to a footing that is based on environmental justice, local democracy and an alternative economic path. The goal is not to undermine a lot of the good work that is happening in the green growth agenda, particularly at the intersection of poverty and environment. What this book offers that is useful is an alternative lens to examine the green growth paradigm and its problematic trajectory of embedding neoliberal capitalist values and structures as the key delivery mechanism for sustainability. This reflects what I see as one of the takeaway messages from the book, that within the green growth paradigm are extreme elements and market forces that have no desire to achieve sustainability. Green Growth: Ideology, Political Economy and the Alternatives is an answer to this problem and a call for action-essential reading for the sustainability practitioner.

Tavis Potts

University of Aberdeen, Department of Geography and Environment, Aberdeen, UK; E-Mail: tavis.potts@abdn.ac.uk 